\title{
Developing the philosophy of recovery in South African mental health services
}

\author{
JS Parker \\ Department of Psychiatry and Mental Health, University of Cape Town and Lentegeur Psychiatric Hospital, Cape Town, South Africa
}

\begin{abstract}
The recovery movement has emerged as an important and powerful force in the design and implementation of mental health care in many countries around the world. This involves new and more positive understandings of the concept of recovery, both as an individual outcome and as a goal of services. The basis for these understandings is examined, with particular emphasis on longterm outcomes in schizophrenia, and a brief history of the origins of the recovery movement is given. An argument is made for the implementation of a recovery framework within South African mental health services.
\end{abstract}

Keywords: Recovery; Mental health services; Schizophrenia; South Africa

Received: 21-06-2012

Accepted: $23-07-2012$

doi: http://dx.doi.org/10.4314/ajpsy.v15i6.51

This article is based on a paper presented at the National Mental Health Summit convened by the Department of Health, Republic of South Africa from 12-13 April 2012.

\section{Introduction}

An important and powerful force in both the design and function of mental health services has emerged in many parts of the world. ${ }^{1}$ This force involves a new conceptualisation of the meaning of recovery. This has implications for how recovery is understood as a clinical term, but more importantly, it critically affects both how individuals who suffer from mental illness see themselves and are perceived by others, as well as how mental health services are designed. In a country such as South Africa where services remain underdeveloped ${ }^{2}$, promoting these new understandings of recovery and working to develop a philosophy of recovery in mental health are critical steps in addressing the burden of illness.

\section{The concept of recovery}

Traditionally, recovery is understood to mean an "absence of disease or, cure"'3 and whilst this may be appropriate for certain acute conditions such as a fractured limb, it can be

\section{Correspondence}

Dr JS Parker

Groote Schuur Hospital, Department of Psychiatry, University of Cape

Town, Anzio Road, Observatory, 7925, Cape Town, South Africa

email: jsparker@pgwc.gov.za argued that it has questionable validity when it comes to conditions that are more chronic or enduring, such as an amputated limb or chronic hypertension. In South Africa we have a very famous example of an athlete who is a double amputee and has qualified for the Olympic Games; it goes without saying that we do not consider him to be "ill" nor do we refer to the many prominent individuals who suffer from chronic hypertension as "patients" in the first instance. Yet, somehow in psychiatry this understanding persists, as do the resultant assumptions that emerge in the way we refer to those who have been diagnosed with a severe mental illness.

If we take the example of schizophrenia, recognised as one of the most severe and chronic mental illnesses and perhaps the one most strongly associated with negative perceptions, there is a growing body of evidence, from long term follow-up studies that such perceptions are not well founded. ${ }^{4}$ Indeed the evidence points to outcomes that are substantially more positive and varied than has been expected traditionally; and these findings suggest that recovery, regardless of how it is defined, can actually be a real possibility 5 for most individuals and not just for a minority. ${ }^{6}$

Perhaps as important as this clinical understanding of what recovery means, is the utility of this meaning for those who have been diagnosed as "mentally ill." Since at least the 1980's, growing numbers of individuals who have selfidentified as suffering from mental illness have spoken against what they perceive as being profoundly negative and disempowering views which they argue have contributed significantly to negative outcomes. ${ }^{7}$ It can further be argued, 
that many well-meaning clinicians have also been negatively affected by these misconceptions, leading to a vicious cycle of negative self-fulfilling prophecies with the inevitable outcomes of loss of hope, burn-out and the resort to cynical and defensive styles of practice.

\section{Origins of the recovery movement}

More recently, perhaps the most influential studies that really began to change thinking about long-term outcomes and rehabilitation, were the Vermont Longitudinal Study ${ }^{8}$ and the Maine and Vermont Comparison Study. ${ }^{9}$ The Vermont study demonstrated remarkably good outcomes in formerly chronic, long-term "backward" patients who had been placed in the community as part of a model rehabilitation program. Thirtytwo years after their first admission, $68 \%$ of the surviving patients in the study had a GAS (forerunner to the GAFGlobal Assessment of Functioning ) score of over 61; and outcomes in a variety of domains were significantly better than those of a comparable group of Maine patients who had been placed in the community under a "dehospitalisation program" involving "traditional care."

As these and other similar findings began to receive more attention, those working to reintegrate people with serious mental illness into society began to shift their focus from pure symptom reduction to an emphasis on functional ability. Inevitably, this led to an increased understanding of rehabilitation as including social and psychological aspects rather than purely medical ones. This in turn involved the realisation that not only was a broader attention to the resources of the individual required, but also to those of the society in which that individual is expected to live - including housing, employment and the way in which health services are rendered. So, as psychosocial rehabilitation gained more currency as a concept, with it came a better understanding of the importance of both consumer choice and of social mobilization. ${ }^{10}$

Alongside these shifts, the 1970's and 1980's saw the emergence of the mental health consumer movement, which entailed the mobilization of increasingly large groups against what was perceived as inhumane and demeaning treatment by mental health services, particularly in large institutions. As this movement gained strength, its members began to speak and write more openly about their difficulties and about their personal experiences of recovery, a term that had already gained considerable currency in the field of physical illness and disability. ${ }^{11}$

\section{Developing the concept of recovery as a vision in mental health services}

In one of the earliest and most influential articles on recovery, William Anthony, a champion of psychosocial rehabilitation, issued a call in 1993 for recovery to become the "guiding vision' behind how we design and implement services for people with psychiatric disabilities. He described it as:

"A deeply personal, unique process of changing one's attitudes, values, feelings, goals, skills, and/or roles. It is a way of living a satisfying, hopeful, and contributing life even with limitations caused by illness. Recovery involves the development of new meaning and purpose in one's life as one grows beyond the catastrophic effects of mental illne.s., "'12
This led to a greater understanding of this multidimensional view of the recovery concept; and in 2004, the US Substance Abuse and Mental Health Services Administration held a consensus congress where the following definition was forged:
"Mental health recovery is a journey of healing and transformation enabling a person with a mental health problem to live a meaningful life in a community of his or her choice while striving to achieve his or her full potential." 13

This has recently been simplified, as follows:
"A process of change through which individuals improve their health and wellness, live a self-directed life, and strive to reach their full potential. '14

Various other definitions have been suggested but perhaps key to all, is an understanding that this concept of recovery is multidimensional and that it involves the interplay between people's experience of their mental health and their circumstances.

\section{Personal and systemic features of recovery}

One can thus understand the vision of recovery as a critical goal that can serve to integrate all efforts to promote healing, from the individual level through to the levels of services and of society in general. On a personal level, Jacobson ${ }^{15}$ emphasises four "internal conditions":

- Hope - as a belief that recovery is possible and as a frame of mind that allows this to occur;

- Healing - as something distinct from cure, as something that emphasises self, as apart from illness and control;

- Empowerment - as a corrective for the sense of helplessness and dependency that comes both with severe mental illness and with prolonged contact with some of the less transformed mental health services;

- Connection - with broader society and with one's roles as part of that society.

To promote these key conditions, Farkas ${ }^{16}$ suggests four key values that promote recovery within services:

- Person orientation

- Person involvement

- Self-determination/self-choice

- Hope

\section{Conclusion}

As many studies and numerous speakers at the Summit have noted, we are faced with major challenges including a high burden of disease ${ }^{17}$ with poor resources, a lack of public awareness with widespread stigmatisation, and an overreliance on both medication ${ }^{18}$ and large institutions. ${ }^{19}$ If we are to turn this situation around, we need a united effort from everybody who has a stake in improved mental health services. This includes consumers, their friends and family members, the multiplicity of non-governmental organisations, and the private and public sectors. Indeed, as awareness improves and stigma is challenged, it will become apparent that improved mental health is everyone's business, and that 
achieving this ultimately involves the empowerment of individuals and the transformation of society that has been the dream of our young democracy. Adopting the vision of recovery as a shared goal is the first step in developing a united and powerful force that will drive the development of the kind of health service and society that we all desire.

\section{Acknowledgements}

The author would like to acknowledge the contributions of members of the Recovery Interest Group of the Western Cape in drawing up the recommendations contained in this article and the Center for Psychosocial Rehabilitation of Boston University for their training and support.

\section{References}

1. Slade M. 100 ways to support recovery: a guide for mental health professionals, Rethink Recovery Series 2009: vol. 1.

2. Jacob KS, Sharan P, Mirza I, Garrido-Cumbrera M, Seedat S, Mari J J, Sreenivas V, Saxena S. Mental health systems in countries: where are we now? Lancet 2007; 370: 1061-77.

3. Torgalsbøen A. What is recovery in schizophrenia? In: Davidson L, Hardin g C, Spaniol L, eds. Recovery From Severe Mental Illnesses: Research Evidence and Implications for Practice. Vol 1. Boston, Mass: Center for Psychiatric Rehabilitation, Sargent College of Health and Rehabilitation Sciences, Boston University; 2005; 302 -315.

4. Bellack A S. Scientific and consumer models of recovery in schizophrenia: concordance, contrasts, and implications. Schizophrenia Bulletin 2006; 32 (3): 432-442.

5. Calabrese J D, Corrigan P W. Beyond dementia precox: findings from long-term follow-up studies of schizophrenia. In: Ralph $O R$ Corrigan P W, eds. Recovery In Mental Illness - Broadening Our Understanding of Wellnes. APA 2005: 63-84.

6. Harrow M, Grossman L, Jobe TH, Herbener ES. Do patients with schizophrenia ever show periods of recovery? A 15-year multifollow-up study. Schizophr Bull. 2005; 31:723-734.

7. Deegan PE. Recovering our sense of value after being labeled. J Psychosoc Nurs Ment Health Serv 1993; 31: 7-11.
8. Harding CM, Brooks GW, Ashikaga T, Strauss IS, Breier A .The Vermont longitudinal study of persons with severe mental illness: I methodology, study sample, and overall status 32 years later. Am J Psychiatry 1987;144:718-726

9. De Sisto M J, Harding C M, McCormick R V, Ashikaga T, Brooks G W. The Maine and Vermont Three Decade Studies of Serious Mental Illness. British Journal of Psychiatry 1995; 167:331-342.

10. Anthony W, Cohen M, Farkas M. Psychiatric Rehabilitation. Boston, Mass: Center for Psychiatric Rehabilitation; 1990.

11. Chamberlin J. Speaking for ourselves. An overview of the expsychiatric inmates movement. Psychosocial Rehabilitation Journal. 1984; 8:56-63

12. Anthony W A. Recovery from mental illness: the guiding vision of the mental health service system in the 1990's. Psychosocial Rehabilitation Journal 1993; 16(4):1 1-23.

13. Substance Abuse and Mental Health Services Administration, (SAMHSA). National Consensus Statement on Mental Health Recovery Definition. http://mentalhealth.samhsa.gov/publications/allpubs/sma05-4129 (accessed 18 July 2012).

14. Substance Abuse and Mental Health Services Administration. (SAMHSA) News Release 12/22/2011: SAMHSA announces a working definition of "recovery" from mental disorders and substance use disorders. http://www.samhsa.gov/newsroom/advisories/ 1112223420. aspx (accessed 18 July 2012).

15. Jaconson N, Greenley D. What is recovery? A conceptual model and explication. Psychiatric Services 2001; 52:482-485.

16. Farkas $M$ The vision of recovery today: what it is and what it means for services. World Psychiatry 2007; 6:1-7.

17. Bradshaw D, Norman R, Schneider M. A clarion call for action based on refined DALY estimates for South Africa. (Editorial) South African Medical Journal 2007; 97:438-440.

18. Petersen I, Bhana A, Campbell-Hall V, Mjadu S, Lund C, Kleintjies S et al. Planning for district mental health services in South Africa: a situational analysis of a rural district site. Health Policy And Planning 2009; 24(2):140-150.

19. Lund C, Flisher AJ. Community/hospital indicators in South African public sector mental health services. The Journal of Mental Health Policy and Economics 2003; 6:181-187.

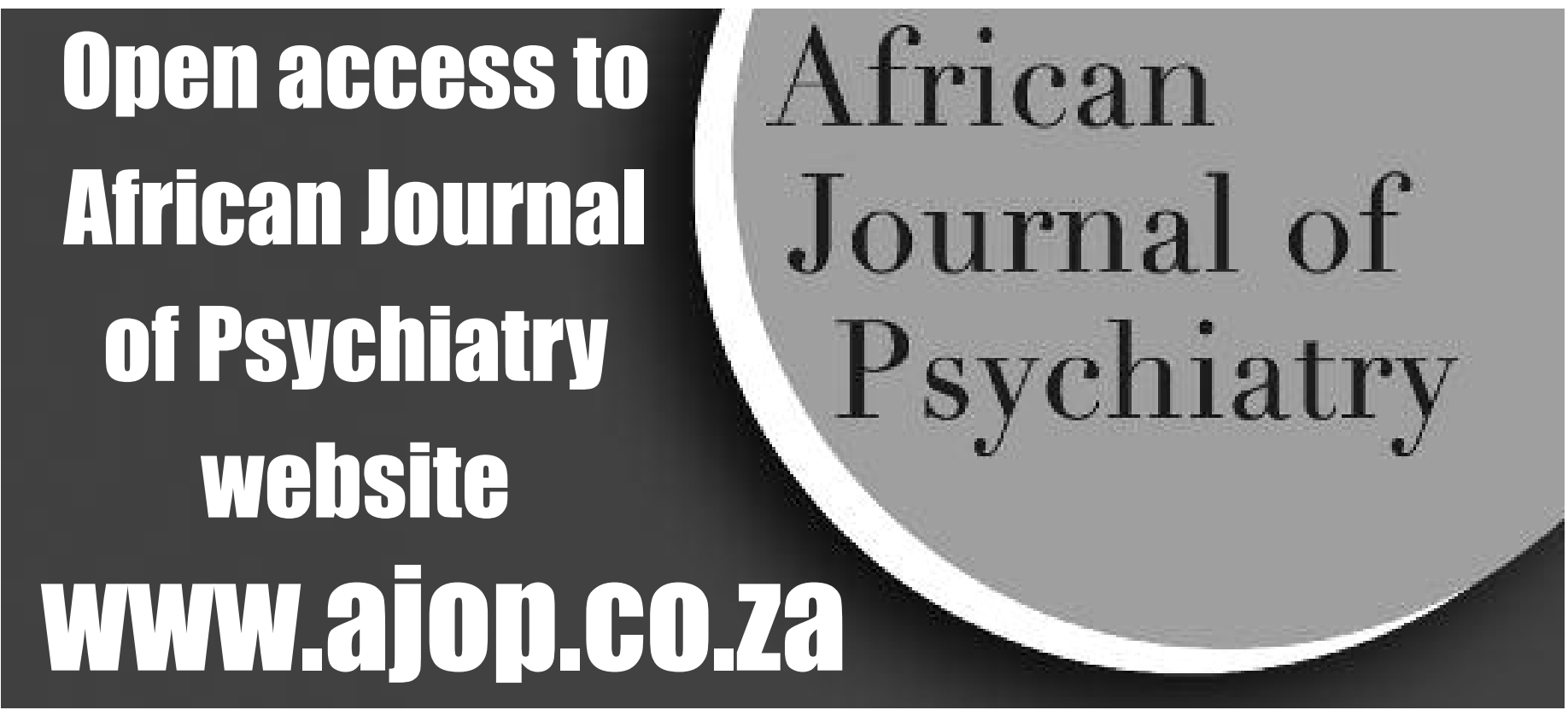

